\title{
Peningkatan Literasi terhadap Lembaga Jasa Keuangan Bank pada Masyarakat Kelurahan Cawang Jakarta Timur
}

\author{
Riwandari Juniasti ${ }^{1}$, Edison Siregar ${ }^{2}$ Lis Sintha Oppusunggu, ${ }^{3}$ Fery Tobing ${ }^{4}$ \\ 1.2.3,4Universitas Kristen Indonesia, Jakarta, Indonesia \\ E-mail : riwandari.juniasti@uki.ac.id; edison.siregar@uki.ac.id; \\ lis.shinta@uki.ac.id; fery.tobing@uki.ac.id
}

\begin{abstract}
Abstrak
Banyak masyarakat telah mengenal lembaga perbankan namun belum semua mampu mengakses bank dan memanfaatkan produk dan jasa perbankan serta paham akan risiko yang dihadapi. Melalui kegiatan Pengabdian kepada Masyarakat di Kelurahan Cawang Jakarta Timur dilakukan edukasi keuangan untuk meningkatkan literasi keuangan masyarakat di Kelurahan Cawang Jakarta Timur terhadap lembaga jasa keuangan bank, produk jasa lembaga jasa keuangan, cara mengakses lembaga keuangan khususnya perbankan, tentang manfaat serta risiko menggunakan produk lembaga jasa keuangan, termasuk memberikan pengetahuan bagaimana mengajukan kredit ke bank, pengetahuan tentang peran Otoritas Jasa Keuangan (OJK) dan Lembaga Penjamin Simpanan (LPS). Metode yang dilakukan adalah melakukan edukasi keuangan dan untuk melihat dampak atas materi yang disampaikan, dilakukan evaluasi berupa pre-test dan post test pada peserta yang hadir di kelurahan tersebut. Hasil PkM menunjukkan bahwa literasi peserta PkM di Kelurahan Cawang Jakarta Timur sudah cukup baik, karena telah mengenal OJK. LPS dan bank serta telah bertransaksi di bank. Setelah dilakukan edukasi keuangan $61,30 \%$ peserta mengalami peningkatan literasi. Peningkatan literasi juga ditentukan oleh jenjang pendidikan, usia dan gender. Peserta PkM dapat dikatakan telah memiliki pengetahuan dan keyakinan tentang lembaga jasa keuangan serta produk dan jasa keuangan, termasuk fitur, manfaat dan risiko, hak dan kewajiban terkait produk dan jasa keuangan.
\end{abstract}

Kata kunci: edukasi keuangan; literasi keuangan; perbankan

\begin{abstract}
Many people are familiar with banking institutions but not all are able to access banks and utilize banking products and understand the risks they face. Through Community Service activities in Cawang Village, East Jakarta, financial education is conducted to improve public financial literacy in Cawang Village, East Jakarta on financial services, financial services products, and how to get access to financial institutions especially banks, including providing knowledge on how to apply for credit to banks, as well as knowledge about the role of the Financial Services Authority (OJK) and the Deposit Insurance Corporation (LPS). The method used is financial education and to see the results of the impact on the material presented, an evaluation is carried out in the form of pre-test and post-test for participants present in the Kelurahan. The results of the PkM show that the literacy of PkM participants in Cawang Village in East Jakarta is quite good, because they already know OJK. LPS and banks and have transacted at banks. After financial education, $61.30 \%$ of participants experienced an increase in literacy. Literacy improvement is also determined by levels of education, age and gender. PkM participants can be said to have knowledge and confidence about financial service institutions and financial products and services, including features, benefits and risks, rights and obligations related to financial products and services
\end{abstract}

Keywords: financial education; financial literacy; banking 


\section{PENDAHULUAN}

Edukasi keuangan adalah salah satu cara untuk meningkatkan literasi keuangan masyarakat, diharapkan dengan semakin tinggi tingkat literasi keuangan masyarakat maka semakin banyak masyarakat yang dapat memanfaatkan produk dan jasa keuangan. Jika masyarakat menggunakan produk dan jasa keuangan serta merasakan manfaatnya maka transaksi keuangan perbankan akan meningkat, transaksi keuangan yang meningkat dapat mendorong pertumbungan ekonomi masyarakat yang nantinya akan menciptakan pemerataan pendapatan.

$$
\text { Literasi keuangan adalah }
$$

pengetahuan, keterampilan, dan keyakinan, yang mempengaruhi sikap dan perilaku untuk meningkatkan kualitas pengambilan keputusan dan pengelolaan keuangan dalam rangka mencapai kesejahteraan, sedangkan yang dimaksud dengan edukasi keuangan adalah serangkaian proses atau kegiatan untuk meningkatkan Literasi Keuangan. Tujuan Literasi Keuangan adalah:

a. meningkatnya kualitas pengambilan keputusan keuangan individu; dan

b. perubahan sikap dan perilaku individu dalam pengelolaan keuangan menjadi lebih baik, sehingga mampu menentukan dan memanfaatkan lembaga, produk dan layanan jasa keuangan yang sesuai dengan kebutuhan dan kemampuan Konsumen dan/atau masyarakat dalam rangka mencapai kesejahteraan

(SEOJK No.30/POJK.07/2017).

Inklusi keuangan adalah ketersediaan akses pada berbagai lembaga, produk, dan layanan jasa keuangan sesuai dengan kebutuhan dan kemampuan masyarakat dalam rangka meningkatkan kesejahteraan (POJK No. 76/POJK.07/2016).

Menurut Otoritas Jasa Keuangan tingkat literasi keuangan di Indonesia dibagi menjadi empat bagian:

1. Well literate, yakni memiliki pengetahuan dan keyakinan tentang lembaga jasa keuangan serta produk jasa keuangan, termasuk fitur, manfaat dan risiko, hak dan kewajiban terkait produk dan jasa keuangan, serta memiliki keterampilan dalam menggunakan produk dan jasa keuangan.

2. Sufficient literate, memiliki pengetahuan dan keyakinan tentang lembaga jasa keuangan serta produk dan jasa keuangan, termasuk fitur, manfaat dan risiko, hak dan kewajiban terkait produk dan jasa keuangan.

3. Less literate hanya memiliki pengetahuan tentang lembaga jasa keuangan, produk dan jasa keuangan.

4. Not literate, tidak memiliki pengetahuan dan keyakinan terhadap lembaga jasa keuangan serta produk dan jasa keuangan, serta tidak memiliki keterampilan dalam menggunakan produk dan jasa keuangan (OJK, 2013).

Masyarakat Jakarta adalah masyarakat dengan tingkat literasi dan inklusi yang tertinggi (40\%) dibandingkan dengan masyarakat di provinsi lainnya. Tingkat preferensi masyarakat terhadap lembaga jasa keuangan tertinggi adalah Perbankan $(66,7 \%)$, namun masyarakat lebih mengenal pinjaman melalui pegadaian $(56,6 \%)$ dibanding melakukan pinjaman melalui bank (Strategi Nasional Literasi Keuangan (Revisit 2017), 2017). Mengajukan pinjaman ke bank masih dianggap sulit oleh sebagian masyarakat. Masyarakat masih banyak yang lebih suka meminjam uang kepada teman, meminta menerima arisan lebih dulu, pelepas uang (rentenir), dan merasa lebih mudah untuk meminjam di koperasi atau menggadaikan barangnya di pegadaian.

Masyarakat di Kelurahan Cawang Jakarta Timur juga merasakan hal yang sama, merasakan sulit mengakses ke bank untuk mendapatkan modal kerja. Berdasarkan data statistik yang dikeluarkan oleh BPS Jakarta Timur tahun 2017, jumlah penduduk Kelurahan Cawang Jakarta Timur 33.781 jiwa, pria berjumlah 17.123 dan wanita 16.658, yang didominasi oleh usia 20 sampai dengan 50 tahun sebanyak 51,02\%. Di Kelurahan ini terdapat 23 sekolah yang terdiri dari 3 SMP, 18 SMA, dan 2 SMK serta 4 Universitas. Disamping itu ada 10 Bank Umum yang siap melayani masyarakat di 
Kelurahan ini. Berdasarkan data yang ada di Kelurahan ini belum ada BPR/BPRS (BPS Kota Administrasi Jakarta Timur, 2017). Untuk itu dirasakan perlu untuk diberikan peningkatan literasi keuangan melalui edukasi tentang lembaga jasa keuangan, produk-produk lembaga jasa keuangan dan cara mengakses lembaga keuangan khususnya perbankan serta manfaat dan risiko menggunakan produk lembaga jasa keuangan bank, termasuk bagaimana mengajukan kredit ke bank dan peran OJK dan LPS. Pemilihan lokasi dikarenakan Universitas Kristen Indonesia telah menjalin kerjasama dengan Kelurahan Cawang Jakarta Timur yang lokasinya berdekatan. Lokasi yang berdekatan membuat kegiatan literasi dapat terus berkelanjutan dan selalu terbuka ruang konsultasi bagi masyarakat Kelurahan Cawang Jakarta Timur yang memerlukan, sehingga UKI dapat lebih efektif dan intensif dalam melayani masyarakat sekitarnya.

\section{METODE}

Pengabdian kepada Masyarakat (PkM) ini dihadiri oleh 65 peserta yang berusia 30 sampai dengan 60 tahun dan 55 orang diantaranya adalah wanita. PkM ini dilaksanakan oleh 4 orang dosen yaitu:
a. Dr. Ir. Edison Siregar, MM
b. Dr. Lis Sintha, SE., MM
c. Fery Tobing, SE., MM
d. Riwandari Juniasti, S.Pd., MM

yang keempatnya adalah dosen Program Studi Perbankan Fakultas Vokasi Universitas Kristen Indonesia. Keempat orang dosen tersebut dibantu oleh mahasiswa yang bertugas mendampingi masyarakat dalam mengisi kuesioner, pretest dan post test. Bank umum juga dihadirkan dalam acara PkM ini yang tujuannya untuk langsung membuka akses ke bank bagi masyarakat yang memerlukan.

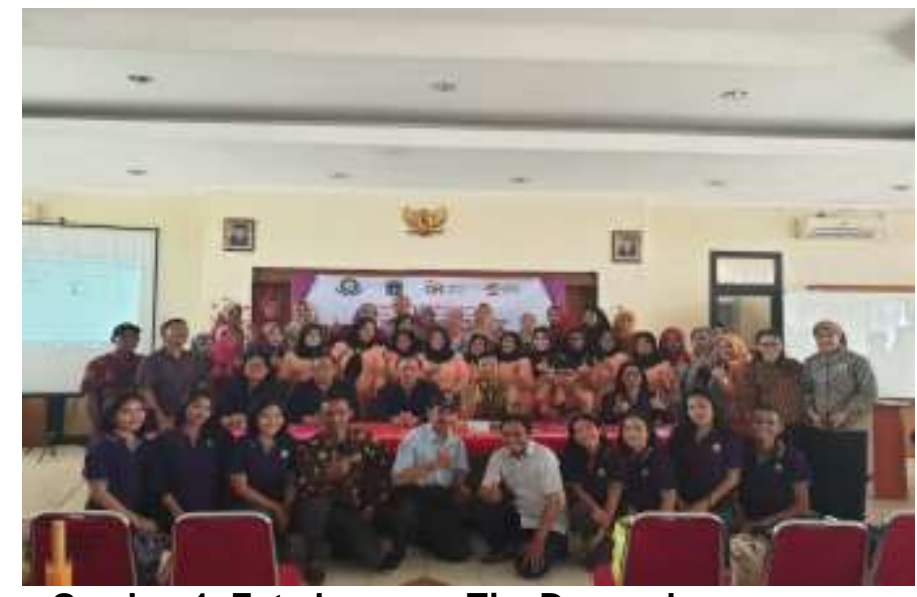

Gambar 1. Foto bersama Tim Dosen dan Mahasiswa

dengan Lurah Cawang Jakarta Timur dan Peserta PkM

serta staf dari Bank BNI dan Bank DKI Sumber: Dokumentasi Pribadi

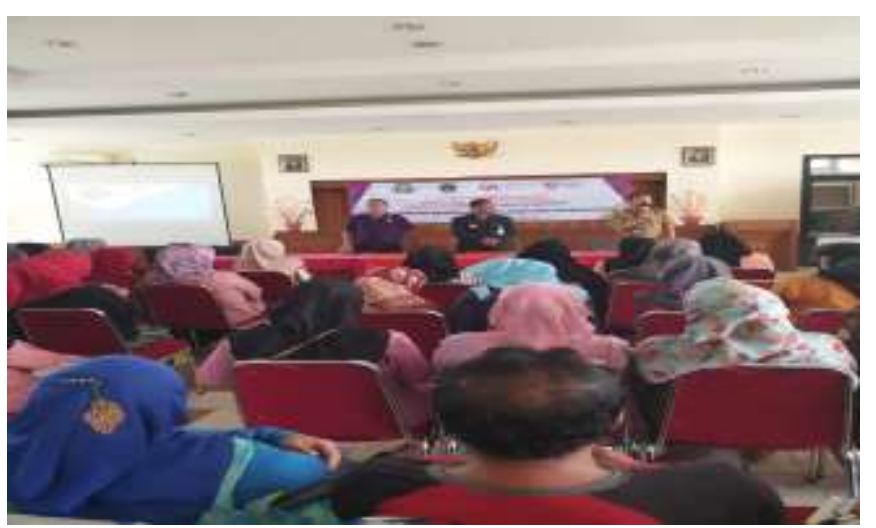

Gambar 2. Pembukaan PkM dihadiri Lurah Cawang,

Dekan Fakultas Vokasi UKI dan Kaprodi Perbankan dan Keuangan FV UKI Sumber: Dokumentasi Pribadi

Materi yang disampaikan pada saat PkM adalah:

1. Maksud dan Tujuan PkM

2. Mengenal Lembaga Keuangan

3. Produk bank

4. Cara menabung dan membuka deposito

5. Mengenal Lembaga Penjamin Simpanan (LPS)

6. Mengenak Otoritas Jasa Keuangan (OJK)

7. Mengajukan kredit di bank

8. Mewaspadai investasi bodong dan pinjaman online

Metode pertama yang dilakukan adalah meminta peserta yang hadir untuk mengisi kuesioner dan pre-test, yang tujuannya adalah untuk mengetahui tingkat literasi peserta sebelum diedukasi. 
Pertanyaan dalam kuesioner dan pre-test dikaitkan dengan materi yang akan disampaikan. Selain pre-test juga dilakukan tanya jawab dengan para peserta yang hadir untuk mencairkan suasana dan juga untuk melihat sampai dimana masyarakat mengenal lembaga jasa keuangan terutama bank.
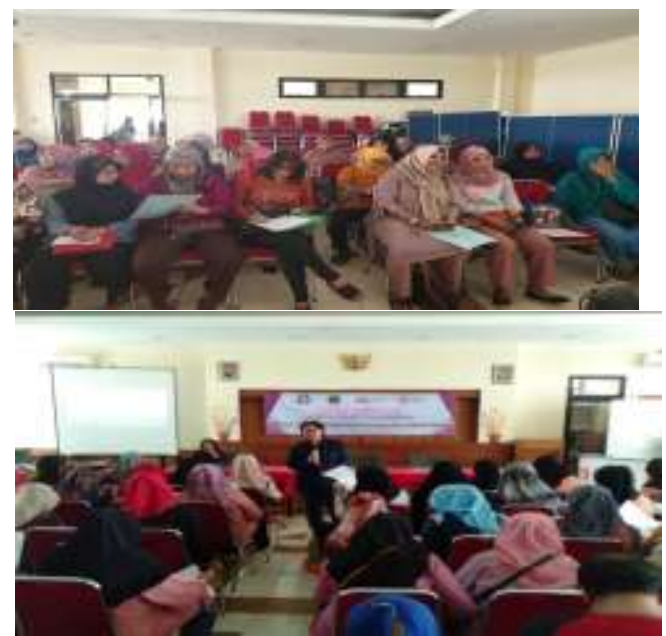

Gambar 3. Mengarahkan peserta untuk mengisi kuesioner dan pretest sebelum edukasi

Sumber: Dokumentasi pribadi

Metode yang kedua adalah melakukan edukasi dengan memaparkan materi edukasi tersebut diatas oleh para dosen yang terlibat dalam PkM ini. Selain menyampaikan materi yang telah disebutkan diatas juga diputarkan videovideo terkait LPS dan OJK, untuk lebih mudah memperkenalkan kedua lembaga tersebut kepada peserta. Setelah itu dibuka kesempatan kepada peserta yang hadir untuk mengajukan pertanyaan. Pertanyaan yang diajukan sebagain besar adalah bagaimana agar bisa mengajukan kredit modal kerja kepada bank dan bagaimana agar terhindar dari investasi bodong dan pinjaman online yang tidak terdaftar di OJK. Pertanyaan dijawab oleh dosen dan juga oleh petugas dari bank umum yang hadir dalam acara tersebut. Pada acara ini juga diberikan kuis-kuis berhadiah untuk menarik minat peserta dalam menjawab pertanyaan terkait materi yang telah diberikan.

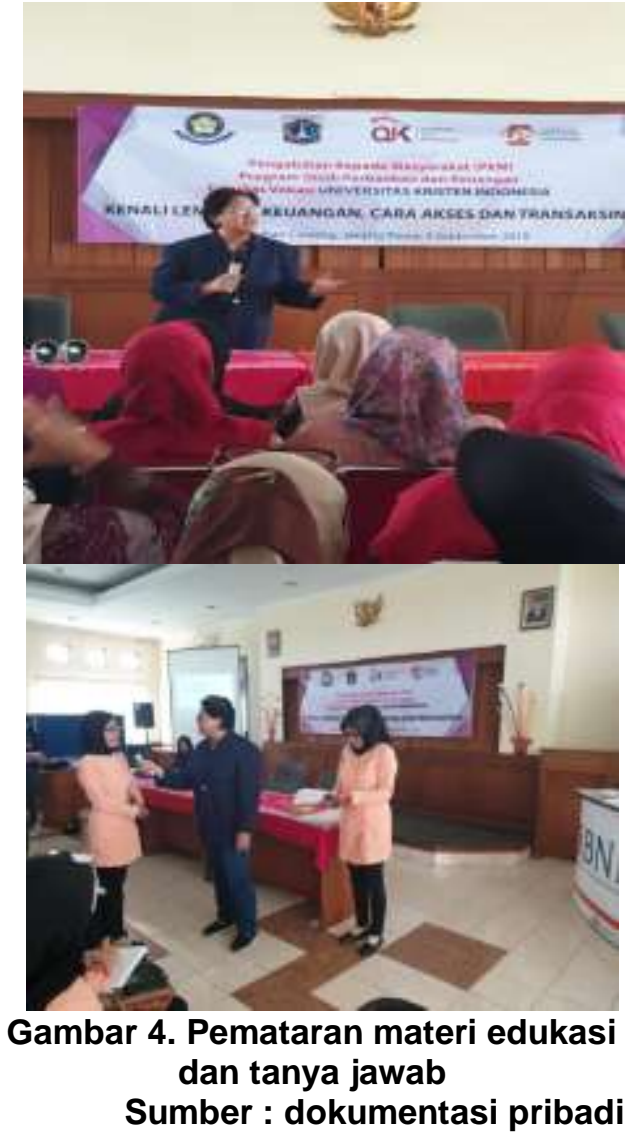

Metode yang ketiga adalah melakukan post test untuk mengetahui apakah terjadi peningkatan literasi setelah peserta mendengarkan semua materi yang disampaikan. Materi post test sama dengan materi pre-test. Peserta juga diminta untuk mengisi lembar evaluasi pelaksanaan PkM untuk perbaikan pelaksanaan kedepan. Dari 65 peserta yang hadir yang mengerjakan pre-test dan post test sebanyak 62 orang, 3 orang hanya mengerjakan pre-test saja. 


\section{HASIL DAN PEMBAHASAN}

Hasil dari kuesioner yang diisi sebelum peserta di edukasi adalah sebagai berikut:

Tabel 1. Lembaga keuangan yang dikenal

\begin{tabular}{|c|l|c|l|}
\hline \multicolumn{4}{|c|}{$\begin{array}{l}\text { LEMBA KEUANGAN YANG } \\
\text { DIKETAHUI }\end{array}$} \\
\hline & $\begin{array}{l}\text { LEMBAGA } \\
\text { KEUANGAN }\end{array}$ & PESERTA & $\%$ \\
\hline 1 & PEGADAIAN & 38 & $61 \%$ \\
\hline 2 & $\begin{array}{l}\text { BANK } \\
\text { UMUM }\end{array}$ & 42 & $68 \%$ \\
\hline 3 & BPR & 32 & $52 \%$ \\
\hline 4 & LEASING & 17 & $27 \%$ \\
\hline 5 & LAINNYA & 11 & $18 \%$ \\
\hline
\end{tabular}

Masing-masing

peserta diperbolehkan memilih lebih dari satu lembaga. Mayoritas peserta sudah mengenal lembaga perbankan, baik Bank Umum maupun BPR, walaupun BPR tidak ada di daerah tersebut. Pegadaian juga dikenal baik oleh peserta, sama seperti halnya kebanyakan masyarakat pada umumnya yang lebih mengenal pegadaian dibanding lembaga keuangan lainnya.

Tabel 2. Lembaga Keuangan pilihan untuk menabung

\begin{tabular}{|c|c|c|c|}
\hline \multicolumn{4}{|c|}{$\begin{array}{l}\text { LEMBAGA PILIHAN JIKA } \\
\text { MENABUNG }\end{array}$} \\
\hline & $\begin{array}{l}\text { LEMBAGA } \\
\text { KEUANGAN }\end{array}$ & $\begin{array}{c}\text { PESERT } \\
\text { A }\end{array}$ & $\%$ \\
\hline 1 & KOPERASI & 13 & $21 \%$ \\
\hline 2 & BANK UMUM & 49 & $79 \%$ \\
\hline 3 & BPR & 7 & $11 \%$ \\
\hline 4 & ARISAN & 20 & $32 \%$ \\
\hline 5 & LAINNYA & 5 & $8 \%$ \\
\hline
\end{tabular}

Menabung di bank umum telah menjadi pilihan peserta yang hadir di Kelurahan ini, artinya sebagian besar peserta telah menabung di bank umum, dan walaupun tidak ada BPR di Kelurahan ini ternyata ada $11 \%$ responden yang menabung di BPR. Sebanyak 32\% dari responden memilih arisan sebagai tempatnya untuk menabung, dan $21 \%$ menabung di koperasi. Masyarakat yang telah menabung ada $91 \%$ dan $86 \%$ menabung di bank, yang telah menabung di bank menyatakan memilih menabung di bank karena merasa aman dibanding menabung di tempat lain.

Tabel 3. Pilihan saat memerlukan modal kerja

\begin{tabular}{|c|c|c|c|}
\hline \multicolumn{4}{|c|}{$\begin{array}{c}\text { PILIHAN JIKA MEMERLUKAN } \\
\text { MODAL KERJA }\end{array}$} \\
\hline & PILIHAN & PESERTA & $\%$ \\
\hline 1 & TEMAN & 11 & $18 \%$ \\
\hline 2 & KOPERASI & 24 & $39 \%$ \\
\hline 3 & PEGADAIAN & 11 & $18 \%$ \\
\hline 4 & BANK & 28 & $45 \%$ \\
\hline 5 & LAINNYA & 11 & $18 \%$ \\
\hline
\end{tabular}

Pilihan peserta saat memerlukan modal kerja adalah bank namun peserta mengeluhkan sulitnya mendapat kredit modal kerja dari bank, oleh karena itu dalam PkM ini diberikan kiat-kiat untuk mengajukan kredit di bank. Selain ke bank, peserta di Kelurahan ini lebih senang mengajukan kredit ke koperasi dibanding kepada pegadaian atau teman.

Pengenalan peserta terhadap LPS dan BI lebih baik dibandingkan dengan OJK, hal ini mungkin disebabkan karena OJK berdiri setelah kedua lembaga tersebut berdiri. Namun bisa saja pengenalan ini sebatas lebih sering mendengar tentang LPS dan BI dibanding dengan OJK, dan $72 \%$ peserta menyatakan telah mengetahui tentang penjaminan LPS dan $72 \%$ memahami kriteria simpanan yang dijamin oleh LPS, seperti yang terlihat pada tabel dibawah ini: 
Tabel 4. Hasil Kuesioner

\begin{tabular}{|l|c|c|}
\hline KETERANGAN & JUMLAH & $\%$ \\
\hline $\begin{array}{l}\text { Sudah pernah mendengar } \\
\text { tentang BI }\end{array}$ & 41 & $63 \%$ \\
\hline $\begin{array}{l}\text { Sudah pernah mendengar } \\
\text { tentang OJK }\end{array}$ & 41 & $63 \%$ \\
\hline $\begin{array}{l}\text { Sudah pernah mendengar } \\
\text { tentang LPS }\end{array}$ & 59 & $91 \%$ \\
\hline $\begin{array}{l}\text { Sudah mengetahui tentang } \\
\text { Peran LPS }\end{array}$ & 52 & $80 \%$ \\
\hline $\begin{array}{l}\text { Sudah mengetahui tentang } \\
\text { 3T syarat penjaminan LPS }\end{array}$ & 47 & $72 \%$ \\
\hline Sudah menabung & 59 & $91 \%$ \\
\hline Sudah menabung di bank & 56 & $86 \%$ \\
\hline $\begin{array}{l}\text { Memilih menabung di bank } \\
\text { karena aman }\end{array}$ & 56 & $86 \%$ \\
\hline
\end{tabular}

Tabel 5. Hasil Literasi Keuangan

\begin{tabular}{|c|c|l|r|}
\hline & $\begin{array}{c}\text { JUMLAH } \\
\text { PESERTA }\end{array}$ & \multicolumn{1}{|c|}{$\begin{array}{c}\text { HASIL POST } \\
\text { TEST }\end{array}$} & $\%$ \\
\hline 1 & 38 & MENINGKAT & $61,30 \%$ \\
\hline & & $\begin{array}{l}\text { TIDAK } \\
\text { MENGALAMI }\end{array}$ & \\
2 & 12 & PERUBAHAN & $19,35 \%$ \\
\hline 3 & 12 & MENURUN & $19,35 \%$ \\
\hline & & & $\begin{array}{r}100,00 \\
\%\end{array}$ \\
\hline & 62 & & \\
\hline
\end{tabular}

Berdasarkan hasil pre-test dan post test didapat hasil bahwa telah terjadi peningkatan literasi keuangan peserta. Sebanyak $61,30 \%$ dari peserta yang hadir mengalami peningkatan pemahaman akan lembaga keuangan bank, OJK, dan LPS. Literasi keuangan juga dipengaruhi oleh usia, gender, tingkat pendidikan, jumlah anak, status menikah dan pengalaman bekerja (Mahdzan, 2013), dan penelitian lain mengatakan semakin tinggi tingkat pendidikan formal seseorang akan mempengaruhi literasi keuangannya, bertambahnya usia tidak mempengaruhi literasi keuangan, semakin tinggi pendapatan usaha, maka literasi keuangannya juga akan mengalami peningkatan (Rasmini, 2018).

Peningkatan sebesar $61,30 \%$ tak lepas dari pendidikan, usia dan gender para peserta yang hadir dalam acara PkM tersebut. Didapat hasil bahwa peserta yang berpendidikan sarjana secara persentase lebih banyak yang mengalami peningkatakan pemahaman, dan wanita lebih mudah ditingkatkan pemahamannya daripada pria dan jika dari usia ternyata usia 30 sampai dengan 50 tahun yang lebih banyak mengalami peningkatan literasinya.

Tingkat literasi peserta yang hadir dalam PkM tersebut telah memiliki pengetahuan dan keyakinan tentang lembaga jasa keuangan serta produk dan jasa keuangan, termasuk fitur, manfaat dan risiko, hak dan kewajiban terkait produk dan jasa keuangan. Walaupun $86 \%$ telah menabung di bank dan 35\% telah menggunakan debit card, namun belum dapat dikatakan well literate, yakni memiliki pengetahuan dan keyakinan tentang lembaga jasa keuangan serta produk jasa keuangan, termasuk fitur, manfaat dan risiko, hak dan kewajiban terkait produk dan jasa keuangan, serta memiliki keterampilan dalam menggunakan produk dan jasa keuangan. Pemilihan menabung di bank belum berdasarkan pada pengetahuan produk dan risiko, namun lebih karena merasa aman menabung di bank.

\section{SIMPULAN}

Tingkat literasi keuangan peserta PkM Kelurahan Cawang Jakarta Timur dapat dikatakan Sufficient literate, karena mayoritas peserta telah mengenal LPS, OJK dan BI. Peserta juga telah mengenal Bank Umum dan BPR, dan telah mempunyai tabungan di bank umum, walaupun masih sebatas menabung di bank karena merasa aman. Simpulan dari kuesioner, pre-test dan post test yang diberikan peserta PkM Kelurahan Cawang Jakarta Timur belum memiliki keterampilan dalam menggunakan produk dan jasa keuangan.

Setelah dilakukan literasi $61,30 \%$ peserta meningkat literasi keuangan. Peningkatan ini juga ditentukan oleh jenjang pendidikan, usia dan gender. Edukasi ini belum bisa membuat semua peserta memahami semua materi yang disampaikan dan membuat peserta untuk memberanikan diri mengajukan kredit ke bank, karena mengajukan kredit ke bank memerlukan persyaratan-persyaratan 
yang harus dilengkapi oleh peserta, serta usaha peserta harus memenuhi persyaratan bank.

Oleh karena itu masih perlu dilakukan edukasi untuk meningkatkan literasi agar para peserta yang hadir dapat menyiapkan usahanya agar layak mendapat kredit modal kerja dari bank. Pelatihan yang perlu diberikan adalah pelatihan yang mampu meningkatkan pengetahuan untuk pengembangan usaha dan pelatihan bagaimana melakukan pencatatan yang baik mengenai transaksi usaha, serta memantapkan pengetahuan mengenai manfaat dan risiko produk dan jasa bank, sehingga dalam memilih bukan hanya karena merasa aman tetapi memilih karena telah mengetahui manfaat dan risikonya.

\section{UCAPAN TERIMA KASIH}

Dengan terlaksananya pengabdian kepada masyarakat di Kelurahan Cawang Jakarta Timur, kami mengucapkan terima kasih kepada:

1. Bapak Lurah Kelurahan Cawang Jakarta Timur dan jajarannya

2. Panitia Dies Natalis Fakultas Vokasi UKI

3. Dekan Fakultas Vokasi UKI

4. Ketua LPPM UKI

Atas kesempatan yang diberikannya sehingga kami dapat melakukan pengabdian kepada masyarakat sebagai wujud Tridharma Perguruan Tinggi.

\section{REFERENSI}

BPS Kota Administrasi Jakarta Timur. (2017). Kramat Jati dalam Angka 2017. (Arbani, Ed.) (1st ed.). Jakarta Timur: Badan Pusat Statistik Kota Jakarta Timur.

Mahdzan, N. S. (2013). The Impact of Financial Literacy on Individual Saving: An Exploratory Study in the Malaysian Context THE IMPACT OF FINANCIAL LITERACY ON INDIVIDUAL SAVING: AN EXPLORATORY STUDY IN THE MALAYSIAN, (January 2013), 53.

OJK. (2013). Literasi Keuangan. Retrieved from https://www.ojk.go.id/id/kanal/edukasi -dan-perlindungan-
konsumen/Pages/Literasi-

Keuangan.aspx

Nadeak, B., Deliviana, E., Sormin, E., Naibaho, L., \& Juwita, C. P. (2019). Pembinaan Ketahanan Pernikahan dan Keharmonisan Keluarga Dengan Tema "The Family Relationship and Intimacy. Jurnal ComunitÃ Servizio: Jurnal Terkait Kegiatan Pengabdian kepada Masyarakat, terkhusus bidang Teknologi, Kewirausahaan dan Sosial Kemasyarakatan, 1(2), 179-185.

Rasmini. (2018). Analisis Literasi Keuangan dan Faktor-faktor yang Mempengaruhinya (Survey pada Pelaku Usaha Mikro, Kecil dan Menengah di Kota Bandung), VIII(2).

Strategi Nasional Literasi Keuangan ( Revisit 2017). (2017).

Simanjuntak, F. N., Purba, L. S. L., Simatupang, N. I., \& Azzahra, S. F. (2019).

Peningkatan PengetahuanKimia dalam Kehidupan Sehari-hari pada Ibu Rumah TanggaPerkotaan Kelas Ekonomi Menengah. JURNAL ComunitÃ Servizio: Jurnal Terkait Kegiatan Pengabdian kepada Masyarakat, terkhusus bidang Teknologi, Kewirausahaan dan Sosial Kemasyarakatan, 1(2), 98-108.

Mangani, K. S., \& Panjaitan, H. (2019). Pemberian Motivasi Tentang Ekonomi Kreatif KepadaMasyarakat Desa. JURNAL ComunitÃ Servizio: Jurnal Terkait Kegiatan Pengabdian kepada Masyarakat, terkhusus bidang Teknologi, Kewirausahaan dan Sosial Kemasyarakatan, 1(2), 80-88.

Sintha, L. (2020). Kinerja Efisiensi Industri Perbankan Indonesia: Bank Pembangunan Daerah. JURNAL MITRA MANAJEMEN, 6(1).

Sintha, L. (2019). Model Earning Dalam Prediksi Kepailitan Bank. Journal of Banking and Finance, 1(1), 1-9. 
Volume 2, Nomor 1, Tahun $2020 \mathrm{Hal}$

Mangani, K. S., \& Panjaitan, H. (2019). Pemberian Motivasi Tentang Ekonomi Kreatif KepadaMasyarakat Desa. JURNAL ComunitÃ Servizio: Jurnal Terkait Kegiatan Pengabdian kepada Masyarakat, terkhusus bidang Teknologi, Kewirausahaan dan Sosial Kemasyarakatan, 1(2), 80-88.

Peraturan:

POJK No. 76/POJK.07/2016 tentang Peningkatan Literasi dan Inklusi Keuangan di Sektor Jasa Keuangan Bagi Konsumen dan/atau masyarakat

SEOJK No.30/POJK.07/2017 tentang Pelaksanaan Kegiatan dalam Rangka Meningkatkan Literasi Keuangan di Sektor Jasa Keuangan 